\title{
O capeláo do rei, o livreiro da Sorbonne, o advogado da corte: livros, bibliotecas e leitura da história na França do século XVI
}

\author{
Fernando Nicolazzi* \\ Universidade Federal do Rio Grande do Sul, Porto Alegre, Rio Grande do Sul, Brasil
}

\section{RESUMO}

Este ensaio trata do tema da leitura da história no século XVI, articulando uma reflexão sobre a emergência da imprensa na França e sobre o papel das bibliotecas humanistas nesse contexto, a partir da relação estabelecida entre três personagens que viveram na França quinhentista: o capelão Gaston Olivier, o livreiro Galliot du Pré e o advogado Pierre Droict de Gaillard. Como pano de fundo para a reflexão proposta, o texto sugere pensar a historiografia não apenas a partir de suas dimensões epistemológicas, mas também considerando sua realidade material ou livresca, isto é, o livro como condição para a prática da leitura da História e, portanto, para o próprio conhecimento histórico.

Palavras-chave: História da historiografia; leitura da História; França quinhentista.

\section{RESUMEN}

Este ensayo trata del tema de la lectura de la Historia en el siglo XVI, articulando una reflexión sobre el desarrollo de la prensa en Francia y sobre el papel de las bibliotecas humanistas en este contexto, a partir de la relación establecida entre tres personajes que vivieron en la Francia de aquel siglo: el capellán Gaston Oliver, el librero Galliot du Pré y el abogado Pierre Droict de Gaillard. Como tela de fondo para la reflexión que se propone, el texto sugiere pensar la historiografía no solo a partir de sus dimensiones epistemológicas, sino también considerar su realidad material o libresca, es decir, el libro como condición para la práctica de la lectura de la Historia y, por lo tanto, para el propio conocimiento histórico.

Palabras claves: Historia de la historiografía; lectura de la Historia; Francia (siglo XVI).

DOI - http://dx.doi.org/10.1590/2237-101X01803607

Artigo recebido em 26 de janeiro de 2017 e aprovado para a publicação em 22 de maio de 2017.

* Professor da Universidade Federal do Rio Grande do Sul. Bolsista de Produtividade em Pesquisa do CNPq. Este ensaio é resultante do projeto Erudição, ceticismo, historiografia: a cultura histórica francesa no século XVI (Bodin, Montaigne, La Popelinière) e foi realizado graças a um período de pesquisas feitas na Bibliothèque Nationale de France, em fevereiro de 2015, com financiamento do CNPq (Edital universal MCTI/CNPq 14/2013). Agradeço ao Luiz César de Sá Júnior pelo posterior auxílio com algumas informaçôes no acervo da BNF. E-mail: fernando.nicolazzi@ufrgs.br. 


\section{ABSTRACT}

This essay studies the reading of History in the sixteenth century, articulating a reflection on the emergence of the press in France, and on the role of humanistic libraries in this context, based on the relationship established between three men who lived in France: the chaplain Gaston Olivier, the bookseller Galliot du Pré, and the lawyer Pierre Droict de Gaillard. As a background for the proposed reflection, the text suggests to think about historiography not only from its epistemological dimensions, but also considering its material or bookish reality, that is, the book as a condition for the practice of reading History, and therefore, for historical knowledge itself.

Keywords: History of historiography; reading of History; 16th-century France.

"Ordenar bibliotecas es ejercer, de un modo silencioso y modesto, el arte de la critica."

Jorge Luis Borges, Junio, 1968

\section{O capeláo do rei: Gaston Olivier e o surgimento da imprensa em Paris}

Gaston Olivier, senhor de Mancy e capelão do rei Henri II, morreu em Paris, na quinta-feira dia 18 de agosto de 1552, antes de chegar aos cinquenta anos de idade. O ocorrido se deu na maison situada em uma pequena rua náo longe da igreja de Notre Dame. Ciente da condição de saúde precária e cioso para que sua residência parisiense, o Hôtel de Mancy, permanecesse em posse da família Olivier, resolveu fazer todos os arranjos necessários para legar seus bens e definir criteriosamente a sucessão do seu patrimônio, com especial cuidado para a casa localizada na rua de Jouy. Herança de seu bisavô, a habitação foi deixada, na falta de herdeiros diretos, ao seu primo germânico e chanceler da França, François Olivier. Todavia, seus anseios não puderam ser mantidos por muito tempo, pois no início do século seguinte, já em 1601, a propriedade foi vendida pelo neto de François para Jean Fourcy, sieur de Chessy. Como registrou a arquivista e paleógrafa Françoise Lehoux, que se ocupou longamente com o inventário dos bens deixados por Gaston Olivier, "o Hôtel de Mancy tornou-se o Hôtel de Fourcy. Todo um passado, e até a lembrança de Gaston Olivier, foi abolido”.

\footnotetext{
${ }^{1}$ LEHOUX, Françoise. Gaston Olivier, aumônier du roi Henri II (1552). Bibliothèque parisienne et mobilier du XVIe siècle. Paris: L'Auteur, 1957, p. 26-27. Ver ainda alguns comentários a respeito deste tipo de pesquisa sobre inventários de bibliotecas em MARTIN, Henri-Jean. What Parisians read in the sixteenth century. In: GUNDERSHEIMER, Werner L. (Ed.). French humanism 1470-1600. Londres: Macmillan, 1969, p. 131-145.
} 
A infelicidade post-mortem de Olivier, no entanto, não parou por aí. Dentre seus bens mais preciosos inventariados nos dias seguintes àquela quinta-feira, encontrava-se uma riquíssima biblioteca com quase 800 volumes catalogados ao longo de três dias pelo libraire juré da Universidade de Paris, Galliot du Pré. Segundo Lehoux, não é possível mais encontrar a maior parte dos livros deixados pelo capeláo. Supóe-se que a biblioteca foi posteriormente transportada para o château de Leuville e que, por ocasião dos episódios de 1789 e do exílio dos proprietários na Inglaterra, tenha sido destruída ou saqueada e dispersa.

A riqueza do acervo de Olivier era considerável. Apenas para fins de comparação, pode-se ter em conta outras bibliotecas francesas do século XVI. Se a Biblioteca do Rei, que será posteriormente transformada em Biblioteca Nacional, continha na década de 1560 cerca de 3.650 obras, outras coleçóes particulares situam melhor a de Olivier, como, por exemplo, a de Guillaume Pélicier, bispo em Maguelone e em Montpellier, morto em 1568, cujo acervo contava com cerca de 580 volumes, e a de Pierre Lizet, magistrado e presidente do Parlamento em Paris, cuja biblioteca foi inventariada quando de sua morte, em 1550, contendo cerca de 500 volumes. $^{2}$ Certamente, esses números são bastante discretos se comparados com aquela que foi considerada "a mais bela biblioteca particular de Paris" na virada do século XVI para o XVII, a saber, a biblioteca de Jacques-Auguste de Thou, também ele presidente do Parlamento de Paris. De Thou nasceu um ano após a morte de Olivier e tornou-se, entre 1593 e 1616, responsável direto pela biblioteca do rei. Em 1617, quando veio a falecer, seu acervo contava com cerca de 6 mil volumes, juntados em condiçóes bastante difíceis ao longo dos anos em que, concomitante às guerras de religião, pôde viajar por diversas regióes na Itália, na Alemanha, nos Países Baixos e na Suíça. Não é despropositado o fato de Gabriel Naudé ter escolhido esta como a biblioteca exemplar em seu Advis pour dresser une bibliothèque, publicado pela primeira vez em $1627 .^{3}$

O valor da coleção de Olivier, porém, não era devido tão somente a sua dimensão numérica, mas igualmente, e talvez mais importante, à variedade e importância dos autores que compunham o acervo. Na sala de estudos de "aspecto voluntariamente severo" do Hôtel de Mancy, diante da mesa redonda e de uma cadeira coberta por um velho tecido de veludo, havia cinco estantes sem portas, cada uma com um pupitre para facilitar a consulta dos volumes: nelas, dividiam lugar autores antigos e modernos, clássicos da oratória, da poesia, da história, da filosofia, junto com diversos autores religiosos e, é claro, versóes distintas do texto bíblico, como a vulgata de São Jerônimo e a edição preparada por Erasmo contendo o texto latino e o grego.

\footnotetext{
${ }^{2}$ LEHOUX, Françoise. Gaston Olivier, aumônier du roi Henri II (1552), op. cit. Para o dado sobre a Biblioteca do Rei, ver BALAYÉ, Simone. La naissance de la Bibliothèque du Roi, 1490-1664. In: JOLLY, Claude (Dir.). Histoire des bibliothèques françaises. Les bibliothèques sous l'Ancien Régime, 1530-1789. Paris: Éditions du Cercle de la Librairie, 2008, p. 91.

${ }^{3}$ REVEL, Jacques. Entre dois mundos: a biblioteca de Gabriel Naudé. In: BARATIN, Marc; JACOB, Christian (Dir.). O poder das bibliotecas. A memória dos livros no Ocidente. Rio de Janeiro: Editora UFRJ, 2006, p. 219 e ss.
} 
Não se sabe ao certo como foi sendo constituído o acervo, mas acredita-se que nem tudo que ali se encontrava tenha sido colecionado pelo capelão. Certamente havia obras que foram legadas pelo seu pai e pelo seu avô, assim como é possível sugerir que grande parte dos volumes fosse oriunda da coleção do seu tio Jean, bispo de Angers e também poeta, morto doze anos antes de Gaston. Assim, qualquer conclusão que se possa tirar a respeito do inventário desta biblioteca deve levar em consideração este detalhe: trata-se de uma coleção constituída ao longo do tempo e formada segundo variados gostos e hábitos de leitura não apenas de um único indivíduo. De todo modo, trata-se de algo relevante para se pensar o universo livresco da primeira metade do século XVI na França, momento em que a imprensa passa a ser difundida no reino.

Quando da morte de Olivier, a invenção ocidental do mecanismo de impressão com tipos móveis já contava com um século de existência. ${ }^{4}$ Sabe-se que o rei Charles VII, assim que ouviu notícias sobre o que se passava em Mainz, onde Gutemberg ensaiava seus experimentos, enviou um emissário para aprender a nova técnica e, quando retornasse, introduzi-la entre os produtores de livros franceses. Nicolas Jenson de fato seguiu para a cidade alemã, lá permanecendo entre 1458 e 1462 . Todavia, com a morte do rei e a aparente falta de interesse de seu sucessor, Louis XI, Jenson acaba por alterar seu trajeto e da Alemanha seguiu direto para a Itália, onde atuou como impressor primeiro em Roma e depois em Veneza, naquele que seria até o final do século XVI o principal centro de produção de livros na Itália.

Tal situação fez com que levasse ainda uma década para a instalação da primeira imprensa em território francês, ocorrida apenas em 1470. O fato se deu em Paris, com a intervenção do humanista de origem germânica Johann Heynlin, ligado à Sorbonne e subvencionado por Guillaume Fichet, professor da Universidade de Paris. Foi por meio destes contatos para além do rio Reno que três impressores alemães, Ulrich Gering, Michael Friburger e Martin Crantz, chegaram a Paris para introduzir, na própria Sorbonne — na biblioteca da universidade, mas sem caráter institucional —, o primeiro ateliê para a ars artificialiter scribendi em território francês. Três anos mais tarde, em Lyon, que virá a ser a segunda principal cidade francesa em termos de produção de livros impressos no século XVI, é instalada a primeira imprensa na cidade e, graças aos trabalhos do editor Barthélemy Buyer e do impressor

\footnotetext{
${ }^{4}$ O livro de Lucien Febvre e Henri-Jean Martin, publicado originalmente em 1958, é bastante instrutivo sobre este processo. Cito aqui a edição inglesa da obra: FEBVRE, Lucien; MARTIN, Henri-Jean. The coming of the book. The impact of printing, 1450-1800. Londres: NLB, 1976, p. 45 e ss. As linhas que se seguem amparam-se também em MARTIN, Henri-Jean; CHARTIER, Roger (Dir.). Histoire de l'édition française. Tome I. Le livre conquérant. Du Moyen âge au milieu du XVIIe siècle. Paris: Promodis, 1982. Outras referências importantes são: HIRSCH, Rudolf. Printing in France and humanism, 1470-80. In: GUNDERSHEIMER, Werner L. (Ed.). French humanism 1470-1600. Londres: Macmillan, 1969, p. 113-130; MARTIN, HenriJean. The catholic reformation and the book (1585-1650). In: The french book. Religion, absolutism, and readership, 1585-1715. Baltimore: John Hopkins University Press, 1996, p. 1-30; MARTIN, Henri-Jean. Histoire et pouvoir de l'écrit, avec la collaboration de Bruno Delmas. Paris: Albin Michel, 1996; CHARTIER, Roger. Leituras e leitores na França do Antigo Regime. São Paulo: Editora da Unesp, 2004.
} 
Guillaume Le Roy, os primeiros textos em língua francesa foram publicados na França. ${ }^{5}$ Desprovida de universidade e com uma clientela bastante diversificada em relação aos leitores eruditos parisienses, o trabalho de edição em Lyon procurava atender à demanda local, onde o latim não era necessariamente a língua principal. Sobre a importância do uso do francês na imprensa lyonnaise, Dominique Coq sugere que ele atuava "como agente de vulgarização relativa (entre o latim e a língua vernacular) e de estandardização de uma cultura difundida mais largamente e mais longe pelo livro impresso". ${ }^{6}$

Assim, ao longo da década de 1470, diversas outras cidades passam a contar com a invenção de Gutemberg: Angers e Toulouse, em 1476; Albi, em 1477; Chablis e Vienne, em 1478; Poitiers, em 1479; Caen, em 1480. Até o final do século XV, cerca de trinta localidades francesas chegaram a possuir imprensas, mas apenas dezessete conseguiram manter seus ateliês. ${ }^{7}$ No caso de Paris, para ficarmos na cidade em que viveu e morreu Gaston Olivier, a situação assume certas singularidades. Após a iniciativa de Heynlin, uma segunda imprensa é instalada na cidade pelos antigos mercadores de livros Petrus Caesaris e Johannes Stoll, em 1473. Em seguida, outro ateliê importante é fundado por Pasquier Bonhomme, pertencente a uma família de livreiros que atuava neste comércio desde 1394. Foi ali que o primeiro texto em francês foi impresso em Paris: Les chroniques de France (Chroniques de Saint Denis), em $1476 .{ }^{8}$

Segundo notas elaboradas por Brigitte Moreau, a cidade possuía, no começo do século XVI, cerca de 50 oficinas de impressão, número que, em 1535, aumentou para 60. No entendimento da autora, a análise dos livros impressos indica, para as primeiras décadas do século XVI, uma importante ampliação no mercado livreiro a partir da qual os volumes de caráter religioso passam a dividir espaço com obras consideradas humanistas. Fichet, por exemplo, havia se encarregado da publicação de autores antigos, como Salústio, Florus, Cícero, Virgílio, e de modernos, como Guarino de Verona e Lorenzo Valla. Essa cena, no entanto, se transformará sensivelmente com o avançar dos anos e dos conflitos opondo huguenotes e católicos: "personagem novo, o livreiro-impressor humanista vai, todavia, desaparecer com as guerras de religião". " Não obstante, o mundo editorial do século XVI verá em Paris um

\footnotetext{
${ }^{5}$ Entre 1470 e 1520, Paris e Lyon respondiam por 80\% da produção de livros na França. DUREAU, Jeanne-Marie. Les premiers ateliers français. In: MARTIN, Henri-Jean; CHARTIER, Roger (Dir.). Histoire de l'édition française. Tome I, op. cit.

${ }^{6}$ A língua falada na regiáo de Lyon variava enormemente entre alguns dialetos vernaculares como, por exemplo, o franco-provençal e o occitânio (langue d'oc). COQ, Dominique. Les incunables: textes anciens, textes nouveaux. In: MARTIN, Henri-Jean; CHARTIER, Roger (Dir.). Histoire de l'édition française. Tome I, op. cit., p. 182.

${ }^{7}$ HIRSCH, Rudolf. Printing in France and humanism, 1470-80, op. cit. Jeanne-Marie Dureau oferece outra data para Albi: 1475, definindo-a como a terceira cidade na ordem de aparição dos ateliês de impressão. DUREAU, Jeanne-Marie. Les premiers ateliers français, op. cit. Ver ainda MARTIN, Henri-Jean; DUREAU, Jeanne-Marie. Années de transition: 1500-1530. In: MARTIN, Henri-Jean; CHARTIER, Roger (Dir.). Histoire de l'édition française. Tome I, op. cit., p. 217.

${ }^{8}$ HIRSCH, Rudolf. Printing in France and humanism, 1470-80, op. cit.

${ }^{9}$ MOREAU, Brigitte. La librairie parisienne du début du XVIe siècle. In: BARBIER, Frédéric; JURATIC,
} 
crescimento considerável: Henri-Jean Martin estima que entre 1501 e 1600 foram feitas 25 mil impressóes totalizando um montante variando entre 12 e 25 milhóes de cópias produzidas na cidade. ${ }^{10}$ Se forem considerados ainda os impressos "importados" para a cidade, que em meados do século tinha cerca de 200 mil habitantes, é possível imaginar um ambiente relativamente dinâmico neste pouco mais de um século desde o ingresso da invenção de Gutemberg em solo francês.

Naquele ambiente, o público leitor era composto em grande parte por pessoas ligadas à universidade, por clérigos, juristas e cortesãos. Gaston Olivier foi um destes leitores. Trata-se de um personagem que, apesar de oficialmente próximo à corte real, não ocupava uma posição de proeminência na história política francesa. Não obstante, o inventário de sua biblioteca permite aventar algumas hipóteses quanto ao mundo do livro e, sobretudo, da leitura na França da metade do século XVI. Os volumes impressos constantes em seu acervo foram publicados entre 1467 e 1552, ou seja, mesmo que a coleção não tenha sido iniciada por ele, Olivier foi acrescentando volumes até os momentos finais de sua vida. Colecionando e lendo seus livros ao longo da primeira metade do século XVI, o capeláo do rei viveu em um período em que o livro impresso tomou formas particulares, emancipando-se do formato dos livros manuscritos até então predominantes, e morreu apenas alguns anos antes de poder ver, no mercado livreiro francês, a superação das publicaçóes em latim pelos livros editados em francês, configurando já um outro ambiente de leitura e ampliando, com isso, o próprio público leitor. $\mathrm{O}$ trabalho realizado após sua morte merece, portanto, atenção, uma vez que a biblioteca inventariada "testemunha, da parte daquele que a recolheu e conservou, uma curiosidade quase universal e um raro ecletismo, passíveis de serem encontrados em um homem eclesiástico dublê de homem cultivado". ${ }^{11}$ A morte do capelão permite que entre em cena, então, o livreiro da universidade.

\section{O livreiro da Sorbonne: Galliot du Pré e uma biblioteca humanista}

Ao longo dos três dias que se seguiram à morte de Gaston Olivier, foi realizado o inventário da sua biblioteca, tendo sido encarregado para a tarefa Galliot du Pré, livreiro da Sorbonne e filho de Jean du Pré, um dos primeiros editores de livros litúrgicos em Paris, conhecido pelas gravuras feitas em metal e em madeira com que ornava suas produções. ${ }^{12}$

Sabine; VARRY, Dominique (Dir.). L'Europe et le livre. Réseuaux et pratiques du négoce de librairie XVIe-XIXe siècles. Paris: Editions Klincksieck, 1996, p. 13-16.

${ }^{10}$ MARTIN, Henri-Jean. What parisians read in the sixteenth century, op. cit. Martin sugere que entre o século XVI e o XVII a edição de cada obra variava de 500 a 1.000 exemplares. MARTIN, Henri-Jean. The catholic reformation and the book (1585-1650), op. cit., p. 3.

${ }^{11}$ LEHOUX, Françoise. Gaston Olivier, aumônier du roi Henri II (1552), op. cit., p. 38-39.

${ }^{12}$ As informaçóes sobre Galliot du Pré foram retiradas de: DELALAIN, Paul. Notice sur Galliot du Pré. Libraire parisien de 1512 à 1561, extraite du Journal Général de l'Imprimierie et de la Librarie, du 6 décembre 


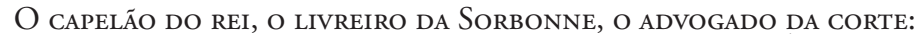
LIVROS, BIBLIOTECAS E LEITURA DA HISTÓRIA NA FRANÇA DO SÉCULO XVI

Fernando Nicolazzi

Galliot atuou no ambiente editorial francês entre 1512 e 1561, notabilizando-se como um inovador nas artes da impressão em Paris. Nas palavras de Annie Charon-Parent, o editor se valia de um "francês depurado e de técnicas de ilustração inovadoras". ${ }^{13}$ Situava-se, assim, em pleno contexto de definição dos contornos assumidos pelo humanismo francês, caracterizado pelo uso de tipos-móveis romanos para a impressão, pelos aspectos gráficos dos livros e pela divulgação de autores franceses escrevendo e publicando em língua vernácula. ${ }^{14}$

Assim como Robert Estienne, ele também filho de um editor ilustre, conhecido pelos dicionários latinos e latim-francês que imprimia em seu ateliê no Quartier Latin e que obteve o título de imprimeur du Roi para grego e hebreu em 153915, Galliot du Pré teve papel considerável na difusão de ideais e de autores humanistas na França, particularmente na versão jurídica do humanismo gaulês. Além de obras de Guillaume Budé, também editadas por Estienne, publicou autores como Hugues Doneau, François Baudoin e Andrea Alciato, todos ligados ao mos gallicus docendi. ${ }^{16}$ Segundo estimativa de Charon-Parent, das 315 obras editadas, 112 eram jurídicas, sendo que em seu estoque, entre os 39.417 volumes, aproximadamente a metade era de obras ligadas ao direito. Publicou também traduçóes de autores antigos como César, Cícero, Tito Lívio, Plutarco, Ovídio, Virgílio, Plínio (o Velho), Diodoro da Sicília, Flávio Josefo, além dos modernos Bocaccio, Alberti, Bembo e Erasmo.

1890. Paris: Cercle de la Librairie, de l'Imprimerie, de la Papeterie etc., 1890; DELALAIN, Paul. Notice complémentaire sur Galliot du Pré. Libraire parisien de 1512 à 1561, extraite du Journal Général de l'Imprimierie et de la Librarie, du 3 octobre 1891. Paris: Cercle de la Librairie, de l'Imprimerie, de la Papeterie etc., 1891; e do quadro sintético "Un éditeur juridique: Galliot du Pré", em MARTIN, Henri-Jean; CHARTIER, Roger (Dir.). Histoire de l'édition française. Tome I, op. cit., p. 244-245.

${ }^{13}$ CHARON-PARENT, Annie. Le monde de l'imprimerie humaniste: Paris. In: MARTIN, Henri-Jean; CHARTIER, Roger (Dir.). Histoire de l'édition française. Tome I, op. cit., p. 244-245.

${ }^{14} \mathrm{O}$ tipo-móvel romano era o estilo gráfico preferido dos autores e leitores humanistas. Como sugerem Febvre e Martin, "a história distintiva do romano foi o triunfo do espírito humanista". FEBVRE, Lucien; MARTIN, Henri-Jean. The coming of the book. The impact of printing, 1450-1800, op. cit., p. 80. Esse estilo de escrita, que se contrapunha à caligrafia gótica dos manuscritos medievais, vinha sendo difundido desde Petrarca e, principalmente, por autores como Coluccio Salutati, Poggio Bracciolini e Niccòlo Niccoli, que idealizavam um formato de livro com letras mais arredondadas e obras com mais espaço para anotaçóes nas margens e nas entrelinhas. A forma humanista de escrita passou a ser conhecida como litterae antiquae ou lettera antica, pois tinha por pretensão assemelhar-se aos admirados textos clássicos (pelo menos segundo a primeira redescoberta dos antigos ocorrida no período carolíngio), e foi posteriormente assimilada aos desenvolvimentos da imprensa. DAVIES, Martin. "Humanism in script and print in the fifteenth century". In: KRAYE, Jill (Ed.). The Cambridge companion to Renaissance humanism. Cambridge: Cambridge University Press, 2007, p. 47-62.

${ }^{15}$ MARTIN, Henri-Jean. Le temps de Robert Estienne. In: MARTIN, Henri-Jean; CHARTIER, Roger (sous la direction de). Histoire de l'édition française. Tome I, op. cit., p. 231-234.

${ }^{16}$ Sobre a escola histórica do direito francês, ver POCOCK, John Greville Agard. Introductory: the French prelude to modern historiography. In: POCOCK, John Greville Agard. The ancient constitution and the feudal law. A study of english historical thought in the seventeenth century. A reissue with a retrospect. Cambridge: Cambridge University Press, 1987, p. 1-29. Ver ainda o clássico estudo de KELLEY, Donald R. Foundations of modern historical scholarship. Language, law, and history in the French Renaissance. Nova York: Columbia University Press, 1970. 
Em 1559, dois anos antes de falecer, editou a obra de André Thévet, Singularités de la France antarctique. ${ }^{17}$

O inventário da biblioteca de Gaston Olivier, portanto, foi feito por alguém que, sem dúvida, estava completamente imerso no mundo do livro e nos ambientes da edição no contexto do humanismo francês. A escolha de du Pré para a tarefa, segundo Françoise Lehoux, indica por si só o valor da biblioteca inventariada. Tratava-se de um acervo composto quase que integralmente por livros impressos em papel; havia dois manuscritos em pergaminho, dois em papel, nove obras impressas em vélin (pele de novilho). Embora não se tenha conhecimento sobre a capacidade de Olivier em ler línguas antigas, encontravam-se ainda cerca de 50 obras em línguas orientais (hebreu, árabe, caldeu) e 33 em grego. Evidentemente, a maior parte dos livros estava impressa em latim, mas du Pré pôde ainda encontrar nas prateleiras do capelão 11 livros em francês, três em italiano e três em espanhol.

Como era de se esperar, em termos de conteúdo predominavam as obras de caráter religioso, sendo a maior parte de teologia, cerca de 225, nas quais se encontravam pais da Igreja, teólogos medievais e autores dos séculos XV e XVI. Embora houvesse ainda textos de reformadores católicos, os livros contra os ideais protestantes eram em maior número. Para Lehoux, isso "denota, entre os Olivier, o desejo de se documentar com fontes autenticamente católicas sobre uma questão que, então, agitava todos os espíritos". ${ }^{18}$ Havia ainda a seção jurídica, em menor número, onde se encontrava o código teodosiano, ediçóes anotadas do Digesto e das Institutiones, além de recolhas de ordenanças reais. Entre as obras consideradas como des lettres, ciências e artes, filósofos antigos e modernos (Platão, Aristóteles, Pico de la Mirandola), poucos oradores (Cícero, Quintiliano) e um número considerável de poetas e historiadores. No campo da poesia, havia autores medievais, mas a maior parte era de clássicos antigos e humanistas. Virgílio dividia espaço com Pontano. Entre historiadores, obras de gregos e latinos (Heródoto, Tucídides, Plutarco, Tito Lívio, Tácito, Suetônio), além de modernos como Polidoro Virgílio, Paolo Emílio de Verona e Robert Gauguin.

Olivier mantinha em suas estantes humanistas como Boccaccio, Angelo Poliziano, Leonardo Bruni, Guillaume Budé, Erasmo, e ainda “ecos da renascença platônica” nos escritos de Marsílio Ficcino. Obras de cabala e filosofia hermética, de ciências naturais e ocultas, de viagens pelo Egito, pela América, por Roma, além de romances e obras dramáticas também encontravam lugar. Enfim, era considerável a tarefa para a qual Galliot du Pré foi chamado: inventariar um acervo volumoso em termos numéricos e bastante variado no que diz respeito às características dos volumes que o compunham.

Anthony Grafton já chamou a atenção para o papel desempenhado pelos livros e pelas bibliotecas na vida de um indivíduo que se dividia entre o humanista e o cortesão na Itália do século XV, particularmente em Ferrara. Para o historiador norte-americano, "encontram-

\footnotetext{
${ }^{17}$ CHARON-PARENT, Annie. Le monde de l'imprimerie humaniste: Paris, op. cit.

${ }^{18}$ LEHOUX, Françoise. Gaston Olivier, aumônier du roi Henri II (1552), op. cit., p. 40.
} 
-se os livros na encruzilhada da vida social e da vida intelectual, e o cortesão a quem faltar o savoir-faire livresco está fadado a fracassar tão vergonhosamente quanto seu confrade que não conhece as normas do Galateo". ${ }^{19}$ Além disso, é preciso considerar também as diferenças entre as formas de uso dos livros nestes espaços que, no alvorecer da modernidade, serviram para colecionar, preservar e até mesmo descartar obras: de um lado, as bibliotecas públicas, lugar para a frequência dos eruditos humanistas e onde o acervo de textos clássicos autorizados poderia ser organizado $;^{20}$ de outro, os studiolos particulares, servindo para a consulta privada do cortesão ou do rei e também para encontros letrados entre indivíduos.

No caso francês do século XVI, as particularidades que a vida cortesã assumia em relação ao contexto das cidades italianas do século anterior colocam a situaçáo em outros termos. Roger Chartier sugere pensar nas diferenças entre uma "biblioteca de príncipe" (bibliothèque de prince) e uma "biblioteca principesca" (bibliothèque princière): a primeira, destinada ao uso pessoal do soberano; a segunda, reunida em nome do soberano e assumindo um certo tom oficial, voltada predominantemente para o uso público. ${ }^{21}$ Tal é a razão pela qual, a partir de 1537, uma ordenança de François I impóe como obrigaçáo aos livreiros e impressores franceses depositar exemplares dos livros publicados no reino na biblioteca localizada no castelo de Blois, o chamado depósito legal. Na década seguinte, as coleçôes guardadas em Fontainebleau e em Blois são reunidas e, nos anos 1570, transportadas para Paris. Segundo Chartier, "as coleçôes assim constituídas têm uma finalidade totalmente 'pública': elas querem ser centros de salvaguarda, que protegem do desaparecimento todos os livros que merecem; estão abertas aos sábios e aos eruditos". ${ }^{22}$ Assim, a organização de acervos, sejam eles formados pelas coleçôes reais, pelas bibliotecas dos humanistas ou da nobreza togada, não se constituem apenas como

um solitarium, um lugar de retiro fora do mundo, e de gozos secretos. Abertas aos literatos, aos eruditos, mesmo aos simples curiosos [...], suas coleçóes de manuscritos e impressos podem ser mobilizadas a serviço do saber, da história da monarquia, da política ou da propaganda do Estado. $^{23}$

Evidentemente, tais consideraçóes não podem ser simplesmente projetadas para o caso de Olivier, já que não disponho de informaçóes a respeito das formas de uso que ele fazia de seu acervo. $\mathrm{O}$ fato é que o número relativamente pequeno de manuscritos e a própria nature-

${ }^{19}$ GRAFTON, Anthony. Como criar uma biblioteca humanista: o caso de Ferrara. In: BARATIN, Marc; JACOB, Christian (Dir.). O poder das bibliotecas. A memória dos livros no Ocidente, op. cit., p. 171.

${ }^{20}$ Grafton destaca o papel de Coluccio Salutati e, depois dele, de Guarino de Verona e Giovanni Lamola, para o entendimento da biblioteca como um "foco da crítica ativa dos textos". Ibidem, p. 174.

${ }^{21}$ CHARTIER, Roger. Patronage et dedicasse. In: CHARTIER, Roger. Culture écrite et société. L’ordre des livres (XIVe-XVIIIe siècle). Paris: Albin Michel, 1996, p. 82.

${ }^{22}$ Ibidem, p. 83.

${ }^{23}$ Ibidem, p. 84. 
za da coleção sugerem um leitor menos erudito do que curioso, alguém buscando nos livros o saber ali oferecido, alguns ensinamentos morais, o resguardo de suas certezas religiosas ou simplesmente o prazer desinteressado na leitura. É difícil, senão impossível, dizer se o capelão do rei era um leitor dedicado como Guillaume Budé ou displicente como Michel de Montaigne, conforme este nos faz crer em alguns de seus ensaios.

O jovem Budé, que aproveitou a paixão (e a condição financeira) de seu pai por adquirir livros, demonstrou sua propensão erudita na leitura feita, por exemplo, da edição florentina de 1488 das obras de Homero. ${ }^{24} \mathrm{O}$ texto, anotado do começo ao fim e linha por linha, trazia nas margens do volume sinais gráficos, abreviaturas e anotações, muitas delas em grego, indicando um caminho de leitura no qual transitavam técnicas mnemônicas e acúmulo bibliográfico. Assíduo frequentador de bibliotecas públicas e privadas, Budé mostrava a paciente erudição humanista em andamento, valendo-se do seu raro domínio da língua grega e dos interesses que emergiam para um jurista francês do século XVI, ocupando sua leitura com questôes puramente eruditas ou legais, mas também com seus usos políticos e julgamentos religiosos. No auxílio dessa primeira leitura impressa nas margens e páginas de seus livros, fazia ainda uso sistemático dos cadernos de anotaçóes que indicavam uma segunda leitura, em alguns casos distinguindo pela cor da tinta os temas e assuntos "fichados". Ou seja, a leitura era para ele uma obra a ser construída com cuidado, um processo e um trabalho que exigia apuro e dedicação. Como ele próprio chegou a afirmar, "eu não poupo despesas para comprar livros e esforços para estudá-los, forçando-me a trabalhar uma hora e meia a cada dia, sem intervalo". ${ }^{25}$

Montaigne, por sua vez, afirmando-se como homem de "alguma leitura" e "nenhuma memória”, e tendo frequentado livros pelas andanças ocasionadas na lide diplomática, decidiu se fechar na biblioteca privada do seu castelo e conviver com as obras que conseguiu juntar ao longo de sua vida. Situada no terceiro pavimento da torre, logo acima da capela e do quarto de descanso, era mobiliada com uma mesa e uma cadeira e tinha um formato redondo que lhe permitia, em um único golpe de vista, contemplar todas as obras organizadas em cinco prateleiras ao longo de toda a sua volta. Ali, no que chamava de "sua sede" (mon siège), passava horas sozinho (menos tempo nos dias de inverno e nunca nas noites), onde procurava "subtrair esse único recanto à comunidade tanto conjugal como filial e social". Sua prática de leitura implicava folhear os volumes, ora uns, ora outros, sem preocupação de definir critérios ou uma ordem específica; seu intuito era antes o prazer causado pela fuga do cotidiano do que a erudição cuidadosa do estudioso: "para distrair-me de uma fantasia importuna (imagination importune), basta recorrer aos livros; eles facilmente me desviam

\footnotetext{
${ }^{24}$ GRAFTON, Anthony. How Guillaume Budé read his Homer. In: GRAFTON, Anthony. Commerce with the classics: ancient books and the Renaissance readers. Ann Arbor: The University of Michigan Press, 1997, p. $135-183$.

${ }^{25}$ BUDÉ, Guillaume. Opera, 1:362, apud GRAFTON, Anthony. How Guillaume Budé read his Homer, op. cit., p. 151.
} 
para si e subtraem-na de mim”. ${ }^{26}$ Ao contrário de Budé, para quem cada passagem obscura se mostrava como um desafio de interpretação, Montaigne evitava qualquer comprometimento erudito: "as dificuldades, se as encontro ao ler, não roo as unhas por causa delas; deixo-as onde estão, depois de fazer-lhes uma investida ou duas". Seu propósito, afinal, era tornar-se "mais sensato (plus sage), não mais sábio (plus savant) ou eloquente". ${ }^{27}$

Assim, na impossibilidade de discorrer sobre as práticas de leitura que encontravam espaço na biblioteca do Hôtel de Mancy, sem saber se elas aproximavam o capelão de Budé ou de Montaigne, o interesse maior para os propósitos aqui ensejados é o de refletir sobre os significados que a organização do inventário feito por Galliot du Pré oferecem à análise historiográfica. $\mathrm{O}$ acervo reunido por Olivier foi constituído em um contexto singular, recortado, de um lado, pelo advento da imprensa a partir da segunda metade do século XV e, de outro, pelas primeiras tentativas mais importantes de se projetar uma biblioteca ideal em termos organizacionais, entre as quais é exemplar o Advis de Gabriel Naudé, já no primeiro quarto do século XVII. Ou seja, uma biblioteca montada entre a difusão massiva de livros e os intentos práticos de se organizar fisicamente essa proliferação de obras. ${ }^{28}$

Não seria forçoso, portanto, encarar o trabalho feito por Galliot du Pré como uma espécie de biblioteca duplicada, "portátil” e "sem muros", para utilizar aqui as expressóes sugeridas por Ann Blair e Roger Chartier. ${ }^{29}$ Se, por um lado, é certo que as funçôes de um inventário post mortem são bastante distintas daquelas que moveram os autores dos livros de lugares-comuns ou das "bibliothèques françaises" (espécie de catálogos de obras e autores) durante o século XVI francês, por outro, o fato de o inventário aqui estudado ter sido elaborado por um livreiro e editor que conhecia profundamente o ambiente humanista na França quinhentista permite avançar na reflexão proposta.

Em primeiro lugar, a maneira pela qual é organizado o inventário é significativa. Não há como afirmar que a classificação proposta pelo livreiro tenha obedecido à organização dos volumes feita por Olivier em suas estantes. Assim, parto do pressuposto de que a divisão temática tenha sido obra do próprio Du Pré, feita segundo uma ordem antes de catalogação bibliográfica, talvez mesmo com interesses comerciais, do que de organização epistemológica. Os livros foram assim distribuídos: "livros de teologia e letras santas"; "outros livros,

\footnotetext{
${ }^{26}$ Essais, 3, III. Tradução consultada: MONTAIGNE, Michel de. Os ensaios III. São Paulo: Martins Fontes, 2001, p. 64 e 63, respectivamente.

${ }^{27}$ Essais, 2, X. Tradução consultada: MONTAIGNE, Michel de. Os ensaios II. São Paulo: Martins Fontes, 2006, p. 117 e 123, respectivamente.

${ }^{28}$ Para uma visão mais abrangente sobre as formas de organização do saber no contexto humanista, cotejando com práticas antigas e não ocidentais, remeto ao livro de BLAIR, Ann. Too much to know. Managing scholarly information before the modern age. New Haven: Yale University Press, 2010.

${ }^{29}$ BLAIR, Ann. Bibliotecas portáteis: as coletâneas de lugares-comuns na Renascença tardia. In: BARATIN, Marc; JACOB, Christian (Dir.). O poder das bibliotecas. A memória dos livros no Ocidente, op. cit., p. 74-93. CHARTIER, Roger. Bibliothèques sans murs. In: CHARTIER, Roger. Culture écrite et société. L'ordre des livres (XIVe-XVIIIe siècle), op. cit., 107-132.
} 
tanto de gramática, poesia, humanidade, história, filosofia como de medicina"; "seguem livros de história encontrados no dito escritório (estude)"; "outros livros, tanto de filosofia, cosmografia quanto de medicina"; "seguem os livros tanto de direito canônico quanto civil"; "seguem os livros em grego"; "outros livros em grego e em latim juntos"; "outros livros entre os quais há em hebraico, grego e latim"; "outros livros em francês"; "seguem os livros em pergaminho, tanto escritos à mão quanto impressos". ${ }^{30}$

A classificação é bastante fluida, mas percebe-se logo algumas singularidades. Em primeiro lugar, a diferença entre obras em papel e aquelas produzidas em pergaminho. Ora, para um contexto de emergência e constituiçãa da imprensa, esta é uma informação importante para se classificar obras, pelos menos aos olhos de um atento impressor de livros. No âmbito temático, embora com contornos bastante imprecisos, podem ser evidenciados quatro grandes campos: religião, direito, línguas, artes liberais (a denominação é minha). Para fins de comparação, pode-se usar o plano para uma biblioteca ideal (parfaite \& accomplie de tous points) que La Croix du Maine ofereceu ao rei Henri III em 1583. Nele, nota-se uma divisão em sete grandes classes (ou ordens): 1) coisas sagradas; 2) artes e ciências; 3) descrição do universo; 4) gênero humano; 5) homens ilustres em guerra; 6) obras de Deus; 7) mélanges; todas organizadas em cem armários ou buffets, cada um contendo cem volumes, formando uma coleção de 10 mil obras, divididas em livros, capítulos, cadernos e lugares comuns, agrupados em ordem alfabética para facilitar a consulta. ${ }^{31}$

A proposta do bibliógrafo ao rei era tratar apenas dos escritores em língua francesa, uma vez que já existia uma considerável quantidade de obras que permitisse tal escolha. Eis uma sutil proximidade em relação ao trabalho feito por Du Pré, que já separava as obras conforme a língua de publicação. Evidentemente, neste ponto a atuação profissional do livreiro foi decisiva, afinal de contas tratava-se de um assunto que dizia respeito, sobretudo, ao universo dos impressores: segundo estimativas, é apenas a partir de 1560 que a impressão de obras em língua francesa passa a prevalecer em relação ao latim, daí a importância da atenção, no inventário, às obras publicadas em francês como um critério distinto daquelas publicadas nas línguas antigas e em latim.

É possível ainda atentar para o lugar conferido à história neste arranjo bibliográfico. No âmbito das artes liberais humanistas de Du Pré, ela aparece misturada entre gramática, po-

\footnotetext{
30 "Livres en theologie et sainctes lettres"; "Autres livres, tant en grammaire, poesie, humanité, histoires, philosophie que medecine"; "S'ensuyvent les livres des histoires trouvez en lad. estude"; "Autres livres, tant de philosophie, cosmographie que medecine"; "Ensuyvent les livres tant en droict canon que civil"; "S'ensuyvent les livres en graec"; "Autres livres graecs et en latin ensemble"; "Autres livres ausquels y a ebreu, graec et latin"; "Autres livres en françoys"; "S’ensuyvent les livres en parchemyn, tant escriptz a la main que de lettres de impression".

${ }^{31}$ LA CROIX DU MAINE, François Grudé, sieur de. Desseins, ou projects, du Sieur de la Croix-Du Manine, presentez au treschrestien Roy de France, et de Polongne Henri III. In: Premier volume de la Bibliothèque du sieur de La Croix Du Maine. Paris: Abel l'Angelier, 1584, p. 507 e ss. Ver ainda MARTIN, Henri-Jean. Classements et conjonctures. In: MARTIN, Henri-Jean; CHARTIER, Roger (Dir.). Histoire de l'édition française, op. cit.
} 
esia, humanidade, filosofia, cosmografia e medicina. Para Du Maine, a história possui uma localização mais precisa, encontrando-se na classe de "artes e ciências", compreendendo um

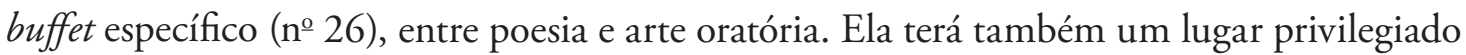
na terceira classe, sobre a descrição do universo, com dois buffets específicos: "história dos franceses ou gauleses" ( $\mathrm{n}^{-}$51) e "história de nosso tempo" (nº 52).

O que é possível de se constatar é que a organização bibliográfica da história não podia simplesmente ser justaposta a sua classificação epistemológica. Se tomarmos como parâmetro o Tableaux accomplie de tous les arts libéraux, idealizado por Christofle de Savigny e publicado em 1587 por seu amigo e advogado do parlamento, M. Bergeron, pode-se notar a localização bastante distante, por exemplo, da gramática e da retórica ou, de modo geral, das artes da palavra. Estas são consideradas pelo enciclopedista como pertencentes ao ramo das artes gerais, enquanto que a história, ligada à teologia, fazia parte das artes especiais, ou seja, aquelas que diziam respeito à natureza das coisas, à vida ou aos costumes. ${ }^{32}$ Isso faz pensar que o uso do termo historia no contexto humanista não era algo tão estável e de fácil precisão, sendo utilizado para referir distintas formas de escrita ou modalidade de saber, indo desde os saberes naturais e médicos até os campos da jurisprudência e da retórica, variando entre a simples descriçấo ou narrativa de fatos até o conhecimento produzido a partir da experiência pessoal, seja ela no campo dos sentidos ou da fé. ${ }^{33}$

O que gostaria de chamar a atençáo é sobre o fato de que os desdobramentos da arte da impressáo na Europa colocaram como imperativo ao mundo letrado o desenvolvimento de formas cada vez mais apuradas de classificação dos livros. Com isso, abre-se uma dupla situação na qual a história se encontra: de um lado, sua condição de saber impõe a reflexão sobre como situá-la diante de outros campos de saber; de outro, sua realidade material, impressa na forma de livro em um contexto de intensa profusáo de obras, torna igualmente relevante o estabelecimento de critérios bibliográficos de classificação. Com isso, se epistemologicamente talvez a história ainda seja um gênero de saber impreciso no século XVI, sem se constituir como disciplina específica com uma localização própria nos campos do conhecimento, no plano livresco as dificuldades de classificação permanecem, mas são, no entanto, de outra ordem: neste caso, tanto o conteúdo do texto quanto o objeto que o suporta são fatores de classificação.

O inventário realizado pelo livreiro da Sorbonne indica, nesse sentido, um interesse não apenas pela história como um gênero particular de escrita, distinto de outros gêneros vizinhos, mas por toda uma cultura histórica que envolve debates teológicos, estudos jurídicos, disputas

\footnotetext{
${ }^{32}$ SAVIGNY, Christofle de. Tableaux accomplie de tous les arts libéraux. Paris: Jean \& François de Gourmont, 1587.

${ }^{33}$ Sobre a profusão de sentidos e significados da história entre os séculos XV e XVII, remeto à importante coletânea organizada por POMATA, Gianna; SIRAISI, Nancy G. (Ed.). Historia. Empiricism and erudition in early modern Europe. Cambridge: The MIT Press, 2005, particularmente ao ensaio de KELLEY, Donald R. Between history and system, p. 211-237.
} 
filosóficas e uma atenção a outras práticas que definem a relação daquela cultura humanista com o passado, tais como o antiquariato e a filologia. Sobretudo, se vista em relação à biblioteca ideal proposta a Henri III, ele mostra uma realidade particular para a história, onde a dimensão do saber assume a materialidade do livro produzido, organizado, classificado.

Os livros inventariados oferecem, assim, alguns poucos indícios sobre o universo da leitura da história na França em meados do século XVI. Entretanto, permanece ainda a imensa distância entre o livro guardado na estante, organizado em inventário, e o livro manipulado pelas mãos, aberto aos olhos e objeto da leitura. A constatação é óbvia: trata-se de tarefa impossível ao historiador reconstituir historicamente as maneiras pelas quais Olivier lia os livros colecionados. Sobretudo, voltando-me ao interesse mais específico aqui explorado, não há como saber nada sobre as leituras que o capeláo fazia dos seus livros de história, o modo pelo qual assimilava e se apropriava das narrativas oferecidas pelos historiadores, como Heródoto, por exemplo, discorrendo sobre gregos e bárbaros, o relato da peste feito Tucídides, ou as narrativas de Polidoro Virgílio ou Paolo Emílio. Esse infortúnio historiográfico não impede, todavia, que o tema da leitura da história seja aqui tratado.

É bem verdade que o caminho agora será um tanto mais tortuoso, afastando-me da biblioteca do capelão e do árduo trabalho feito pelo livreiro. Permaneço, porém, no ambiente parisiense, terreno fértil onde muitos frutos da história foram colhidos por indivíduos notadamente interessados em refletir sobre como a história poderia ou deveria ser lida. Entre eles, um advogado da corte que publicou, quase três décadas após o falecimento de Olivier, um método que se deve ter para a leitura da história.

\section{O advogado da corte: Pierre Droict de Gaillard e a leitura da história}

A preocupação com a leitura da história não era algo necessariamente estranho para um indivíduo letrado do século XVI na França, uma vez que sua escrita e o interesse pelos relatos sobre o passado atravessaram um período de intensas transformaçóes no contexto decorrente das Guerras da Itália. Chantal Grell traça um caminho para a cultura histórica francesa entre o fim do século XV e o início do XVIII que segue desde o momento da "fascinação com o modelo italiano" do humanismo, passando pela fase de questionamento dessa influência em busca de uma "via 'francesa" ligada aos campos da erudição jurídica, seguindo por uma crise política e por conflitos religiosos, quando a unidade do reino encontra-se fragilizada e a história emerge como "único instrumento eficaz para reunir os franceses e superar os ódios", culminando em um ambiente de desenvolvimento do classicismo em que "a pesquisa erudita torna-se um fim em si mesma e a análise filológica perde seu ardor de inovação". ${ }^{34} \mathrm{De}$

\footnotetext{
${ }^{34}$ GRELL, Chantal. História e historiadores na França, das guerras da Itália à morte de Louis XIV. Anos 90, v. 21, n. 39, p. 101-104, 2014.
} 
todo modo, neste período, em que o século XVI ocupa uma posição central, “a história está verdadeiramente no coração do pensamento humanista e seu sucesso se confirma ao longo destes dois séculos" ${ }^{35}$

Como não poderia deixar de ser, a autora destaca o papel importante que a imprensa teve para a difusão das obras historiográficas em suas múltiplas modalidades, como crônicas, anais ou as "velhas histórias". O movimento é certamente duplo: de um lado, os historiadores ampliam seu público leitor, de outro, sua própria prática erudita se transforma. Segundo suas palavras, "a disposição das páginas, a forma material dos volumes, induzem a novas práticas de leitura e de trabalho, uma nova apropriação do saber, facilitador por capítulos, sumários, índex, notas, que permitem uma localização rápida e evitam a leitura in extenso". As consequências disso residem, para a estudiosa francesa, no incremento das condiçóes de legitimidade do saber histórico, embora, talvez, um tanto sobrevalorizados: "os textos impressos são, por outro lado, dignos de fé; cuidadosamente relidos e corrigidos, é possível citá-los e cada um pode consultá-los. O historiador consegue, desde então, mostrar (apporter) as provas" ${ }^{36}$

Outras formas de produção do saber e distintas práticas de leitura impunham ao humanista francês uma reflexão fundamental: como ler as histórias? O filósofo e jurista Jean Bodin foi dos autores que enfrentou a questão, publicando em 1566 um dos principais tratados de artes historicae daquele contexto, o Methodus ad facilem historiarum cognitionem, uma "bagunçada, mal-intitulada obra-prima da geografia histórica”, conforme a definição dada por Anthony Grafton. ${ }^{37}$ Articulando a noção de método com o tema da leitura, Bodin oferece em seu tratado uma série de consideraçóes voltadas para os leitores no sentido de organizarem o material textual diante do qual se colocavam, justamente em um contexto de considerável profusão de impressos. Como já indicou Marie-Dominique Couzinet, “o Methodus é uma resposta específica a um problema específico, o do afluxo do material 'histórico' sob forma de textos tanto quanto de informaçôes indiretas que é preciso gerenciar para utilizá-las". ${ }^{38}$

Diante de uma situação em que, como sugeriu Grafton, havia "enchentes de informação (floods of information)" no ambiente letrado europeu, a intenção de Bodin é facilitar o trabalho de seleção, compilação e leitura, de modo que o leitor interessado náo fique a esmo percorrendo "comentários ao infinito" e consiga escolher os textos mais adequados com o

\footnotetext{
${ }^{35}$ Ibidem, p. 78.

${ }^{36}$ Ibidem, p. 80-81.

${ }^{37}$ GRAFTON, Anthony. What was history? The art of history in early modern Europe. Cambridge: Cambridge University Press, 2007, p. 121.

${ }^{38}$ COUZINET, Marie-Dominique. La Methodus ad facilem historiarum cognitionem: histoire cosmographique et méthode. In: ZARKA, Yves Charles (Dir.). Jean Bodin: nature histoire, droit et politique. Paris: PUF, 1996, p. 25. Ver ainda BLAIR, Ann. Reading strategies for coping with information overload, ca. 15501700. Journal of the History of Ideas, v. 64, n. 1, 2003.
} 
auxílio do "melhor critério". ${ }^{39}$ Dessa maneira, "entendendo que a história é o fundamento moral e prático para a gestáo da res publica, fornecedora de liçóes práticas e de ensinamentos morais, ler bem a história não significa apenas compreender seu fatos, mas igualmente compreender os discursos sobre os fatos" ${ }^{40}$ A arte da história, portanto, equivale para Bodin à arte do bom governo:

porque a maior parte da história é consagrada a explicar a constituição e as mudanças das repúblicas, segue-se que convém expor brevemente os começos, as condiçóes e o fim dos impérios para melhor penetrar na história. As ciências morais não oferecem aliás nenhum exercício que seja mais fecundo e frutuoso, ainda que todos os outros contribuam a ornar o espírito e a formar os modos do homem de uma maneira tão bela quanto notável. Mas tudo isso que a leitura dos historiadores nos ensina sobre os começos, o crescimento, a prosperidade, o declínio e a ruína das cidades é tão necessário aos particulares e às sociedades que Aristóteles não conhecia nada de mais eficaz para fundar e conservar as cidades do que ser instruído na ciência do governo. ${ }^{41}$

Em certa medida, nosso advogado da corte, com seu próprio Méthode quion doit tenir em la lecture de l'histoire, publicado originalmente em 1579, mantém-se dentro deste mesmo contexto traçado por Jean Bodin, definindo as condiçóes da leitura da história segundo a perspectiva da administração e do governo. ${ }^{42}$ De acordo com as informaçóes oferecidas por Claude Gilbert Dubois, o letrado francês "é um homem da burguesia em curso de promoção, ou da pequena nobreza de toga, que se endereça à grande nobreza de espada, refletindo sobre os problemas políticos e sociais aos quais toda ação militar deve estar subordinada" ${ }^{43}$ Os leitores de história aos quais se dirige são, portanto, aqueles que atuam nos negócios públicos do reino.

\footnotetext{
${ }^{39}$ BODIN, Jean. La méthode de l'histoire. In: BODIN, Jean. Ouvres philosophiques de Jean Bodin. Texte établi, traduit et publié par Pierre Mesnard. Paris: PUF, 1951, p. 313.

${ }^{40}$ NICOLAZZI, Fernando. Como se deve ler a história: Jean Bodin e a ars historica do século XVI. In: NICOLAZZI, Fernando et alii. (Orgs.). Aprender com a história? O passado e o futuro de uma questão. Rio de Janeiro: Editora FGV, 2011, p. 224.

${ }^{41}$ BODIN, Jean. La méthode de l'histoire, op. cit., p. 349.

${ }^{42}$ GAILLARD, Pierre Droict de. Methode qu'on doit tenir en la lecture de l'histoire, vray miroir \& exemplaire de nostre vie. Où les principaux poincts des sciences Morales \& politiques rapportez à la loy de Dieu, \& accommodez aux moeurs de ce temps, sont contenus, \& illustrez des plus beaux exemples tirez des histoires, tant sacrees que prophanes. Avec deus tables, l'une des chapitres, \& l'autre des choses memorables contenues en ce livre. A Paris, chez Pierre Cauellat, MDLXXX [1580].

43 DUBOIS, Claude Gilbert. La méthode qu'on doit tenir en la lecture de l'histoire (1579) de Pierre Droict de Gaillard. In: BOHLER, Danièle; SIMONIN, Catherine Magnien (Ed.). Écritures de l'histoire (XIVe-XVIe siècle). Actes du colloque du Centre Montaigne. Bordeaux, 19-21 septembre 2002. Genebra: Droz, 2005, p. 362.
} 
Embora seja difícil de situar com precisão a posição ocupada por Gaillard no cenário social e intelectual francês do século XVI, não seria de todo despropositado esboçar minimamente este ambiente a partir das constataçóes dadas por George Huppert a respeito da relação entre a gens de robe e o desenvolvimento da erudição histórica em tal contexto. Segundo o autor, a nobreza de toga era formada por indivíduos treinados no ensino do direito, cuja carreira atingia seu ápice quando do ingresso em algum dos parlamentos espalhados pela França. Sua contribuição para os estudos históricos, ligada intimamente ao desenvolvimento da escola francesa do direito (mos gallicus juris docendi), relacionava-se com as pesquisas antiquárias e com a coleta e edição de fontes medievais, sobretudo de caráter jurídico. ${ }^{44} \mathrm{Nas}$ palavras de Huppert, "na corte, nos salons literários e científicos, nas cátedras acadêmicas e nas câmaras dos parlements e chambres des comptes - onde a erudição clássica era a chave que abria todas as portas - neste mundo de mandarins dos humanistas franceses, a erudição histórica floresceu em uma grande erupção de atividade bem publicizadas (a great burst of well-publicized activity). ${ }^{45}$

Além disso, voltando às informaçôes de Dubois, Gaillard se mostrava ainda "um humanista periodicamente esclarecido, que cita recorrentemente Erasmo e fornece um alicerce intelectual para uma ética da moderação em todas as coisas e para o respeito de certas regras de ação ligadas à dignidade do homem". ${ }^{46}$ Pois este parece ser o tema que atravessa todo volume escrito por Gaillard, ao estabelecer, desde o início de seu Méthode, o mote do livro: "conhece-te a ti mesmo" (cognoy toy-mesme). Seu intuito é "conduzir como que pelas mãos" os indivíduos interessados na antiguidade, a partir da recolha por ele realizada de temas retirados de autores hebreus, gregos e latinos. Ou seja, Gaillard se coloca ele próprio como um leitor instruído capaz de guiar outros leitores, oferecendo a eles seu próprio método de leitura das histórias que, segundo um topos recorrente no período, eram encaradas a partir da dignidade, da utilidade, da facilidade e do deleite que proporcionam.

Assim, seguindo os traços daquilo que Donald Kelley definiu como o "historicismo" do século XVI, ${ }^{47} \mathrm{o}$ advogado retira das histórias sacras e profanas diversos elementos capazes de fundamentar os planos correlatos da moral e da política, adaptados aos "costumes" (moeurs) daquele contexto, e voltados para um público que se mostrava bastante variado, visto que a história "se comunica a todo tipo de gente, aos artesãos, gens'd'armes, mesmo às mulheres". ${ }^{48}$ Ciente do ambiente livresco em que se encontra e considerando que a materialidade do livro

\footnotetext{
${ }^{44}$ Sobre isso, remeto aos dois estudos já citados de POCOCK, John Greville Agard. Introductory: the French prelude to modern historiography, op. cit., e KELLEY, Donald R. Foundations of modern historical scholarship, op. cit.

${ }^{45}$ HUPPERT, George. The idea of perfect history. Historical erudition and the historical philosophy in Renaissance France. Urbana: University of Illinois Press, 1970, p. 7 (trechos em francês no original).

${ }^{46}$ DUBOIS, Claude Gilbert. La méthode qu'on doit tenir en la lecture de l'histoire (1579) de Pierre Droict de Gaillard, op. cit., p. 363.

${ }^{47}$ KELLEY, Donald R. Foundations of modern historical scholarship, op. cit.

${ }^{48}$ GAILLARD, Pierre Droict de. Methode..., op. cit., p. 25.
} 
é algo relevante na prática da leitura, Gaillard adverte ao seu próprio leitor (ou leitora) sobre o fato de que sua obra mantém nas margens os lugares, exemplos e autoridades nos quais se ampara para elaborar seus argumentos. ${ }^{49}$

Partindo de três referências principais (Platão, Aristóteles e Cícero), Gaillard sustenta sua definição de história recorrendo à fórmula ciceroniana da historia magistra vitae, desdobrando-a nos capítulos II, III e IV cada um dos seus elementos: testemunha dos tempos, luz da verdade, vida da memória, mensageira da antiguidade e, finalmente, mestra da vida. Náo obstante, por trás disso tudo o autor não deixa de reconhecer os desígnios da obra divina, considerando Deus o grande artífice do teatro do mundo, motivo pelo qual refuta o "erro" de Aristóteles quando o filósofo sugeriu que os astros celestes sempre estiveram presentes e, portanto, anteriores à Criação. Dessa maneira, a testemunha dos tempos é buscada por Gaillard a partir da contraposição entre perspectivas cristãs e pagãs, distinguindo Moisés como o primeiro historiador propriamente dito e Heródoto, primeiro historiador pagão, como simples continuador dos esforços feitos pelo primeiro.

A partir dali, Gaillard segue em um apanhado dos autores antigos, passando por Tucídides, Xenofonte, Diodoro da Sicília, Tito Lívio, Suetônio, Josefo, Eusébio, entre outros. Sua preocupação é o correto estabelecimento da cronologia que remete, como já dito, à obra de Criação divina. Por isso que, se a história é a testemunha dos tempos, o relato testemunhal por excelência é feito pelos historiadores, cuja tarefa se mostra como "governanta da prudência” (nourrice de la prudence). ${ }^{50}$ Assim, Gaillard articula a moral cristã com a dimensão política implicada no estudo da história, cuja principal utilidade, estabelecida por autores "pagãos" como Tucídides e Políbio, reside em fornecer bons exemplos para a correta condução dos negócios públicos. Ler histórias é uma prática fundamental, portanto, pois permite um ganho de experiência que, do contrário, apenas ocorreria com a passagem dos anos e o envelhecimento dos indivíduos. Em outras palavras, "a leitura da história iguala os jovens aos velhos em prudência, luz das outras virtudes, a qual, no entanto, seria muito miserável se fosse adquirida apenas por uso (par usage) e não pelo conhecimento das histórias". ${ }^{51}$

Prudente é o leitor capaz de ler com proveito os textos históricos que lhe são oferecidos, tornando-se igualmente apto ao bom governo dos homens. Dessa maneira, o autor concede à história uma posição privilegiada diante das outras artes liberais, pois é apenas através dela que a experiência, quando não pela vivência propriamente dita, pode ser adquirida. Por essa razão se faz necessário um método adequado de leitura da história que

\footnotetext{
${ }^{49}$ Anthony Grafton já mostrou a história das formas de citação bibliográfica na cultura ocidental, que encontraram nas margens, além do rodapé, um espaço importante para se mencionar as referências utilizadas. GRAFTON, Anthony. The footnote: a curious history. Cambridge: Harvard University Press, 1998. Ver ainda a interessante história da página que o historiador americano escreveu: GRAFTON, Anthony. La page. De l'antiquité à l'ère du numérique. Paris: Hazan; Louvre Éditions, 2012.

${ }^{50}$ GAILLARD, Pierre Droict de. Methode..., op. cit., p. 40.

${ }^{51}$ Ibidem, p. 44.
} 
passa a equivaler, nesse sentido, como o gesto mesmo de ver os acontecimentos diante de si. No entanto, a leitura é uma modalidade de visão mais vantajosa, uma vez que possibilita potencializar o próprio gesto: seguindo Philippe de Comines, Gaillard afirma que "nós podemos ver mais coisas em um único livro em três meses do que conseguiriam ver, com seus próprios olhos, vinte homens vivendo seguidamente um após o outro". ${ }^{52} \mathrm{Ou}$ seja, ler história é uma atividade que propicia certa transcendência temporal, já que amplia a capacidade de experiência de um indivíduo ao mesmo tempo que acelera seu processo de amadurecimento. Não seria forçoso relacionar essa perspectiva oferecida pelo advogado com todo o contexto de profusão de impressos que permitiu, com velocidade até então inédita, um acesso maior aos livros e aos textos históricos. Tal é a razão porque Gaillard oferece suas consideraçóes sobretudo à nobreza francesa, levando em conta o papel da formação pela leitura da história como fundamental em função do seu status social e do papel que desempenha no "theatre de la chose publique".

A definição de história assumida por Gaillard, em que pese o fato de estar amparada na fórmula estabelecida por Cícero, cristianizando-a, acresce a ela uma dimensão própria do seu contexto intelectual, isto é, sua dimensão livresca: "o livro dos vivos, e a descrição das coisas feitas e passadas: o som da trombeta pela qual aqueles que estão mortos há tempos e, como ressuscitados e tirados de seus sepulcros, são trazidos à luz" ${ }^{53}$ A partir dessa perspectiva, situa a história em uma posição privilegiada, fazendo uma distinção importante entre filosofia moral e teologia cristã: se esta apresenta a vontade de Deus, aquela trata de temas que permitem conduzir o homem à virtude civil e política. Por essa razão, a filosofia moral encontra-se dependente da leitura da história, ao passo que ler história é uma forma também de aprender a ser cristão. Dessa forma, o autor articula os três eixos fundamentais da sua reflexão: a base cristã do pensamento, o amparo dos preceitos estabelecidos pela filosofia moral, os exemplos tirados da história, colocando nesta a base para as outras duas modalidades.

Ler história, portanto, é a atividade fundamental para o bom governante que, para ser bom, deve naturalmente seguir os preceitos cristãos. Daí a exortação, compreendida no capítulo 15 da obra, à toda a nobreza da França para que se dedique ao conhecimento das letras e da jurisprudência. O fato importante a se considerar é que, neste caso, amar as letras é também desenvolver apreço pelos livros. Para tanto, o autor sugere aos nobres franceses que abandonem seus hábitos medievais (moeurs Gothiques) de odiar as letras e os letrados, "como se os livros e as armas fossem coisas incompatíveis". ${ }^{44} \mathrm{O}$ exemplo vem de César, "um dos maiores guerreiros que já existiu", que, em certa ocasião, fugindo dos seus inimigos no Egito, conseguiu escapar a nado, carregando em uma das mãos o livro que estava compondo. ${ }^{55} \mathrm{Em}$ tempos mais recentes e próximos do autor, embora anterior ao advento da imprensa, Charles

\footnotetext{
${ }^{52}$ Ibidem, p. 46.

${ }^{53}$ Ibidem, p. 53 (itálico meu).

${ }^{54}$ Ibidem, p. 231.

${ }^{55}$ Idem.
} 
V ocupa um lugar de proeminência nesse assunto: nomeado sábio e defensor das letras e dos letrados, fez traduzir para o francês vários autores importantes, como Aristóteles, Cícero e mesmo o texto das sagradas escrituras.

Realidade livresca e existência epistemológica conferem à ideia de história assumida por Gaillard seu lugar diante da cultura histórica do século XVI. Todo o capítulo 33 é destinado à discussão da história em relação às "outras disciplinas", como filosofia moral, teologia, jurisprudência, dialética e retórica: "e, para dizer em uma palavra, todas as disciplinas não tomam sua fonte e origem dos princípios que temos da natureza, mas sim da história, como de uma fonte muito abundante". ${ }^{56}$ Assim, encerrando suas consideraçóes, o advogado da corte recorre às formulaçóes de Jean Bodin sobre a leitura da história, destacando o prazer e o contentamento com essa prática. Todavia, trata-se de um prazer que deve ser dosado criteriosamente, como quando se frequenta um banquete, tratando de escolher com cuidado as carnes que serão ingeridas, para náo consumir apenas as mais saborosas em detrimento da própria saúde.

Por fim, Gaillard destaca a importância do papel da escrita como garantidora da permanência dos fatos para a posteridade, recorrendo à conhecida passagem de Platão sobre as relaçôes entre escrita e memória contida no Fedro. Para o autor francês, em um contexto em que os livros de aide-mémoire ocupam lugar de importância para os sábios e eruditos, "a brevidade de nossa vida, a prolixidade das ciências, a infinita multiplicidade dos negócios mostram por uma experiência infalível, que não podemos viver sem as letras, invenção que atribuímos aos primeiros homens". ${ }^{57}$ Por tal razão, a história pressupóe necessariamente a escrita, que, por sua vez, apenas encontra sentido na leitura dos livros que precisam ser conservados. Daí o elogio feito à monarquia francesa, que empregou largas somas para a organização da Biblioteca de Fontainebleau. Não seria forçoso, por isso, considerar que, se o tivesse conhecido, Gaillard teria feito consideráveis elogios aos esforços realizados pelo capeláo do rei ao formar sua coleção de livros, cuidadosamente catalogada pelo livreiro da Sorbonne.

A aproximação aqui feita entre os três personagens permite, portanto, aventar a hipótese de que, ao se tratar de uma determinada cultura histórica, além dos princípios epistemológicos que a organizam, é importante considerar igualmente as condiçóes materiais que a tornam possível. Isso não quer dizer que ambas as coisas sejam plenamente justapostas, mas torna plausível sugerir que uma não existe sem a outra, seja na forma da complementaridade, seja como algo apenas parcialmente correlato. A profusão de livros impressos colocou certos desafios para os letrados humanistas aqui estudados. Do mesmo modo, não são poucos os que hoje indagam sobre os desafios que uma cultura digital coloca aos historiadores e historiadoras que se debruçam sobre variados passados e diferentes experiências históricas.

\footnotetext{
${ }^{56}$ Ibidem, p. 552.

${ }^{57}$ Ibidem, p. 563. 
Este ensaio foi todo escrito sem que a tinta fosse impressa no papel e seu destino, porventura, será o de permanecer vagando na forma de dados numéricos imateriais, jamais encontrando amparo em alguma prateleira de biblioteca. As condiçóes e formas para a sua leitura, os princípios para sua organização, os modos pelos quais pode ser guardado ou armazenado serão, certamente, variados em relação à situação colocada para o capelâo, para o livreiro e para o advogado que viveram no século XVI. De todo modo, talvez caiba por fim uma constatação que parece funcionar para ambos os casos: se organizar bibliotecas pode ser realmente considerado uma forma de crítica, como sugere a epígrafe colocada acima, do mesmo modo o bom crítico é aquele capaz de organizar, de forma criteriosa e com proveito, as leituras dos livros que serão feitas nas suas próprias bibliotecas, sejam elas físicas ou virtuais.

\section{Fontes primárias}

BODIN, Jean. La méthode de l'histoire. In: BODIN, Jean. Ouvres philosophiques de Jean Bodin. Texte établi, traduit et publié par Pierre Mesnard. Paris: PUF, 1951.

GAILLARD, Pierre Droict de. Methode qu'on doit tenir en la lecture de l'histoire, vray miroir \& exemplaire de nostre vie. Où les principaux poincts des sciences Morales \& politiques rapportez à la loy de Dieu, \& accommodez aux moeurs de ce temps, sont contenus, \& illustrez des plus beaux exemples tirez des histoires, tant sacrees que prophanes. Avec deus tables, l'une des chapitres, \& l'autre des choses memorables contenues en ce livre. A Paris, chez Pierre Cauellat, MDLXXX [1580].

LA CROIX DU MAINE, François Grudé, sieur de. Desseins, ou projects, du Sieur de la Croix-Du Manine, presentez au treschrestien Roy de France, et de Polongne Henri III. In: Premier volume de la Bibliothèque du sieur de La Croix Du Maine. Paris: Abel l'Angelier, 1584. LEHOUX, Françoise. Gaston Olivier, aumônier du roi Henri II (1552). Bibliothèque parisienne et mobilier du XVIe siècle. Paris: L’Auteur, 1957.

MONTAIGNE, Michel de. Os ensaios III. São Paulo: Martins Fontes, 2001.

. Os ensaios II. São Paulo: Martins Fontes, 2006.

SAVIGNY, Christofle de. Tableaux accomplie de tous les arts libéraux. Paris: Jean \& François de Gourmont, 1587.

\section{Referências bibliográficas}

BALAYÉ, Simone. La naissance de la Bibliothèque du Roi, 1490-1664. In: JOLLY, Claude (Dir.). Histoire des bibliothèques françaises. Les bibliothèques sous l'Ancien Régime, 15301789. Paris: Éditions du Cercle de la Librairie, 2008. 
BLAIR, Ann. Reading strategies for coping with information overload, ca. 1550-1700. Journal of the History of Ideas, v. 64, n. 1, 2003.

. Bibliotecas portáteis: as coletâneas de lugares-comuns na Renascença tardia. In: BARATIN, Marc; JACOB, Christian (Dir.). O poder das bibliotecas. A memória dos livros no Ocidente. Rio de Janeiro: Editora UFRJ, 2006.

. Too much to know. Managing scholarly information before the modern age. New Haven: Yale University Press, 2010.

CHARON-PARENT, Annie. Le monde de l'imprimerie humaniste: Paris. In: MARTIN, Henri-Jean; CHARTIER, Roger (Dir.). Histoire de l'édition française. Tome I. Le livre conquérant. Du Moyen âge au milieu du XVIIe siècle. Paris: Promodis, 1982.

CHARTIER, Roger. Bibliothèques sans murs. In: CHARTIER, Roger. Culture écrite et société. L'ordre des livres (XIVe-XVIIIe siècle). Paris: Albin Michel, 1996.

. Patronage et dedicasse. In: CHARTIER, Roger. Culture écrite et société. L'ordre des livres (XIVe-XVIIIe siècle). Paris: Albin Michel, 1996.

. Leituras e leitores na França do Antigo Regime. São Paulo: Editora da Unesp, 2004.

COQ, Dominique. Les incunables: textes anciens, textes nouveaux. In: MARTIN, HenriJean; CHARTIER, Roger (Dir.). Histoire de l'édition française. Tome I. Le livre conquérant. Du Moyen âge au milieu du XVIIe siècle. Paris: Promodis, 1982.

COUZINET, Marie-Dominique. La Methodus ad facilem historiarum cognitionem: histoire cosmographique et méthode. In: ZARKA, Yves Charles (Dir.). Jean Bodin: nature histoire, droit et politique. Paris: PUF, 1996.

DAVIES, Martin. Humanism in script and print in the fifteenth century. In: KRAYE, Jill (Ed.). The Cambridge companion to Renaissance humanism. Cambridge: Cambridge University Press, 2007.

DELALAIN, Paul. Notice sur Galliot du Pré. Libraire parisien de 1512 à 1561, extraite du Journal Général de l'Imprimierie et de la Librarie, du 6 décembre 1890. Paris: Cercle de la Librairie, de l'Imprimerie, de la Papeterie etc., 1890.

. Notice complémentaire sur Galliot du Pré. Libraire parisien de 1512 à 1561, extraite du Journal Général de l'Imprimierie et de la Librarie, du 3 octobre 1891. Paris: Cercle de la Librairie, de l'Imprimerie, de la Papeterie etc., 1891.

DUBOIS, Claude Gilbert. La méthode qu'on doit tenir en la lecture de l'histoire (1579) de Pierre Droict de Gaillard. In: BOHLER, Danièle; SIMONIN, Catherine Magnien (Ed.). Écritures de l'histoire (XIVe-XVIe siècle). Actes du colloque du Centre Montaigne. Bordeaux, 19-21 septembre 2002. Genebra: Droz, 2005.

FEBVRE, Lucien; MARTIN, Henri-Jean. The coming of the book. The impact of printing, 1450-1800. Londres: NLB, 1976. 
GRAFTON, Anthony. How Guillaume Budé read his Homer. In: GRAFTON, Anthony. Commerce with the classics: ancient books and the Renaissance readers. Ann Arbor: The University of Michigan Press, 1997.

. The footnote: a curious history. Cambridge: Harvard University Press, 1998.

. Como criar uma biblioteca humanista: o caso de Ferrara. In: BARATIN, Marc; JACOB, Christian (Dir.). O poder das bibliotecas. A memória dos livros no Ocidente. Rio de Janeiro: Editora UFRJ, 2006.

- What was history? The art of history in early modern Europe. Cambridge: Cambridge University Press, 2007.

. La page. De l'antiquité à l'ère du numérique. Paris: Hazan; Louvre Éditions, 2012.

GRELL, Chantal. História e historiadores na França, das guerras da Itália à morte de Louis XIV. Anos 90, v. 21, n. 39, 2014.

HIRSCH, Rudolf. Printing in France and humanism, 1470-80. In: GUNDERSHEIMER, Werner L. (Ed.). French humanism 1470-1600. Londres: Macmillan, 1969.

HUPPERT, George. The idea of perfect history. Historical erudition and the historical philosophy in Renaissance France. Urbana: University of Illinois Press, 1970.

KELLEY, Donald R. Foundations of modern historical scholarship. Language, law, and history in the French Renaissance. Nova York: Columbia University Press, 1970.

. Between history and system. In: POMATA, Gianna; SIRAISI, Nancy G. (Ed.). Historia. Empiricism and erudition in early modern Europe. Cambridge: The MIT Press, 2005.

MARTIN, Henri-Jean. What Parisians readin thesixteenth century. In: GUNDERSHEIMER, Werner L. (Ed.). French humanism 1470-1600. Londres: Macmillan, 1969.

MARTIN, Henri-Jean; CHARTIER, Roger (Dir.). Histoire de l'édition française. Tome I. Le livre conquérant. Du Moyen âge au milieu du XVIIe siècle. Paris: Promodis, 1982.

MARTIN, Henri-Jean. Classements et conjonctures. In: MARTIN, Henri-Jean; CHARTIER, Roger (Dir.). Histoire de l'édition française. Tome I. Le livre conquérant. Du Moyen âge au milieu du XVIIe siècle. Paris: Promodis, 1982.

. Le temps de Robert Estienne. In: MARTIN, Henri-Jean; CHARTIER, Roger (Dir.). Histoire de l'édition française. Tome I. Le livre conquérant. Du Moyen âge au milieu du XVIIe siècle. Paris: Promodis, 1982.

. The catholic reformation and the book (1585-1650). In: MARTIN, Henri-Jean. The french book. Religion, absolutism, and readership, 1585-1715. Baltimore: John Hopkins University Press, 1996.

. Histoire et pouvoir de l'écrit, avec la collaboration de Bruno Delmas. Paris: Albin Michel, 1996. 
MARTIN, Henri-Jean; DUREAU, Jeanne-Marie. Années de transition: 1500-1530. In: MARTIN, Henri-Jean; CHARTIER, Roger (Dir.). Histoire de l'édition française. Tome I. Le livre conquérant. Du Moyen âge au milieu du XVIIe siècle. Paris: Promodis, 1982.

MOREAU, Brigitte. La librairie parisienne du début du XVIe siècle. In: BARBIER, Frédéric; JURATIC, Sabine; VARRY, Dominique (Dir.). L'Europe et le livre. Réseuaux et pratiques du négoce de librairie XVIe-XIXe siècles. Paris: Editions Klincksieck, 1996.

NICOLAZZI, Fernando. Como se deve ler a história: Jean Bodin e a ars historica do século XVI. In: NICOLAZZI, Fernando et alii. (Orgs.). Aprender com a história? O passado e o futuro de uma questão. Rio de Janeiro: Editora FGV, 2011, p. 224.

POCOCK, John Greville Agard. Introductory: the French prelude to modern historiography. In: POCOCK, John Greville Agard. The ancient constitution and the feudal law. A study of english historical thought in the seventeenth century. A reissue with a retrospect. Cambridge: Cambridge University Press, 1987.

POMATA, Gianna; SIRAISI, Nancy G. (Ed.). Historia. Empiricism and erudition in early modern Europe. Cambridge: The MIT Press, 2005.

REVEL, Jacques. Entre dois mundos: a biblioteca de Gabriel Naudé. In: BARATIN, Marc; JACOB, Christian (Dir.). O poder das bibliotecas. A memória dos livros no Ocidente. Rio de Janeiro: Editora UFRJ, 2006.

\section{Como citar}

NICOLAZZI, Fernando. O capelão do rei, o livreiro da Sorbonne, o advogado da corte: livros, bibliotecas e leitura da história na França do século XVI. Topoi. Revista de História, Rio de Janeiro, v. 18, n. 36, p. 584-607, set./dez. 2017. Disponível em: <www.revistatopoi.org>. 